\title{
Person-centered approach in teaching financial mathematics to students of higher educational institutions
}

\author{
I.S. Vinnikova ${ }^{1 *}$, E.A. Kuznetsova ${ }^{2}$, and E.V. Shpilevskaya ${ }^{3}$ \\ ${ }^{1}$ Minin Nizhny Novgorod State Pedagogical University, Nizhny Novgorod, Russia \\ ${ }^{2}$ Minin Nizhny Novgorod State Pedagogical University, Nizhny Novgorod, Russia \\ ${ }^{3}$ The All-Russian State University of Justice (RLA of the Ministry of Justice of Russia), Rostov-on- \\ Don, Russia
}

\begin{abstract}
The article discusses the need for purposeful, personalityoriented teaching of financial mathematics to students of higher education. The authors have identified the advantages of a student-centered education system that contribute to the formation of a high-quality financial and economic education of a student of a higher educational institution.
\end{abstract}

\section{A problem statement}

The goal of higher education at present is not the total amount of acquired knowledge, skills, and abilities, but an active stock of general cultural, general professional and professional competencies that ensure education at a modern level, self-realization of each student and his successful adaptation in the future. The formation of the competencies inherent in the federal educational standards of higher education is impossible, in our opinion, without a person-centered approach to learning and, in particular, in relation to the discipline "Financial Mathematics".

The specificity of this discipline lies in the structure of the material, its presentation to students and the need for applicants to have basic training in the fields of economic sciences and mathematical calculations. The lack of an individual approach in assessing the knowledge of students at the beginning of the study of this discipline, as a rule, leads to incomplete assimilation of the material and low indicators of overall academic performance.

The decisive role in the organization of work in the study of this discipline belongs to the teacher, who should not work with students in the total number of a group or the whole course, but with a specific person, taking into account his individual abilities, with the development of strengths and taking into account weaknesses. The main task in this case of the teacher is to teach, through the use of the best qualities of the student, his creative abilities, to teach to analyze and critically evaluate the information received, to instill the skills of search work, to give the opportunity to think "strategically" and successfully master the methods of financial discipline $[1,2]$.

* Corresponding author: ipcs-profped@yandex.ru 
It should be noted that the discipline "Financial Mathematics" allows from the first lessons to determine the range of problems that impede the process of successful study, which are typical for most students. The sources of such problems, as a rule, are a low level of knowledge of mathematical foundations and a lack of understanding of the nature of economic processes. Because of this, the task of the teacher, by identifying the gaps in the education of students, is to build classes taking into account the results of the entrance control and to organize the study of the material in a format that is comfortable for students.

\subsection{The objective of the work}

According to the studied works of Soviet and Russian scientists studying the phenomenon of student-centered learning, its foundations were laid for secondary schools [3, 4, 5]. And the main idea is as follows: "the idea of student-centered learning assumes the recognition of the student as the main subject of the learning process, while the goal of designing student-centered learning is to develop the individual abilities of the student" [6]. Another Soviet teacher S.L. Soloveichik in his book "Pedagogy for All" defined the main guidelines of pedagogical activity: "We are raising not a child, but a person. A person within a person. Personality. The inner world of a person is his personality "[7]. The main feature that characterizes student-centered learning is the position taken by the student. "Personallyoriented learning is learning in which students are the subjects of learning and their own development" [8]. That is, not only by the subjects of learning, but more broadly - by the subjects of their own development. The application of these provisions for higher education is an important task in the development of education. And for the implementation of the goals and objectives of the discipline "Financial Mathematics" is urgently necessary.

In student-centered learning, the main educational sources are discipline and the process of mastering it. The study of new material is based on the learning experience of the student, which ensures its success in the implementation of search or research activities [9, 10]. But it is precisely these types of activity, search and research, that are laid down in the process of finding solutions to certain problems, and especially problems in financial mathematics.

In the traditional system, the student is an object of learning. In developing learning, students are already placed in the position of subjects of learning, which in itself does not yet ensure the subjectivity of their own development. Thus, developing education, in our opinion, is a component of personality-oriented education. Personally-oriented learning, incorporating the main task of developmental learning, enhancing the cognitive activity of students, is focused on enriching the student's experience, related both to the material in question and to the process of working with it. "With personality-oriented learning, every child has the opportunity to include his own personal functions in the learning process, his subject experience becomes in demand ..." [11]. Therefore, student-centered learning should find application in the implementation of problems in financial mathematics. It involves considering the features of each financial problem, methods for solving it, using general approaches when working with any problem, analyzing the difficulties of students, typical and atypical errors in the course of solving the problem, formulating conclusions on how to overcome them and, most importantly, to prevent them.

In addition, an important stage in the educational process is the stage of knowledge actualization. In student-centered learning, the teacher must provide students with the opportunity to take initiative, motivating any type of activity, that is, each student must try to answer the question of why this particular task will be considered right now, this type of work will be performed. The key concept of student-centered learning is the subjective experience of students, therefore the stage of updating knowledge is associated with the systematization and generalization of what was learned. At this stage, students' 
mathematical and financial experience is taken into account. "Working in a lesson with a student's subject experience requires special preparation from the teacher: not just a presentation of his subject, but an analysis of the content that students have on the topic of the lesson" $[12,13]$.

\section{Materials and the results of the research}

The main result of the presented research is the use of a student-centered approach in the study of "Financial Mathematics" in higher education in order to increase the effectiveness of learning. For this, the teacher must organize the educational process and the activities of students in such a way that they go to the implementation of the set goal, without his direct guidance. In this case, students independently perform tasks, and the teacher acts only as a consultant, directing their activities in the right direction, giving the opportunity to choose their own individual trajectory of the learning process using control measures to adjust the learning strategy. Building a personal learning strategy within the discipline makes it possible to develop introspection, critical assessment of one's own knowledge, and identify areas requiring in-depth additional study.

In contrast to traditional education in the system of student-centered learning, the function of a lesson in financial mathematics and the form of its organization change significantly. The lesson involves not only the communication and verification of the knowledge gained, but, most importantly, the identification of the knowledge and experience of students in relation to the content of the material presented by the teacher. For this, the teacher, working with a group of students, selects various individual ideas and meanings, and, relying on them, selects those that are most consistent with the scientific content of knowledge, subject to assimilation. The task of the teacher in the system of personal learning is not coercion, but persuading students to accept the content that is laid down by the discipline program [14].

When using this approach to teaching, students do not just master the basic provisions of financial mathematics, but understand how they are obtained, to what extent they correspond not only to scientific knowledge, but also to personally significant values. In the classroom, the main forms of lectures in financial mathematics are such as lecturesconversations, lectures-discussions, where the students themselves act as speakers and cospeakers, and the teacher acts as a facilitator. The teacher deliberately enters into a dialogue with one or more students. At the same time, the rest are a kind of spectators of this process, but not passive, but actively thinking about the subject of an organized conversation, taking one or another point of view and formulating their answers to questions. The activity of students who are not directly involved in the conversation is based on interest in the topic, the very process of dialogue and the personality of the lecturer. That is, in personality-oriented learning, the function of the motive in the appropriation of the content of educational activity radically changes. "In many ways, it is the motive that determines the content itself (meaning is understood, meaning is accepted), which becomes the product of interaction between subjects of educational activity, ascending to the level of personal value" [11]. The content of topics in financial mathematics is born as knowledge, which is owned not only by the teacher, but also by the student, there is a kind of exchange of knowledge, a collective selection of content.

The presence of a discussion platform within such a discipline allows students to pronounce theoretical material, consider the processes of calculating financial indicators from several positions, act as a teacher for other students, which gives a great return in terms of in-depth understanding of the material and its consolidation. At the same time, the discussion allows you to play around with many options for solving problems of a financial and economic nature, propose alternative solutions and choose the most effective one in 
terms of maximizing (optimizing) profit based on the results of a financial transaction or reducing the time spent on using funds to achieve the planned level of profit [15].

Let us dwell on financial problems solved by students in financial mathematics. A task is a goal that needs to be achieved under certain conditions. Conditions specified in a financial task can include indications of a goal and conditions for achieving it. In financial tasks, the goal of an action is what is sought, expressed by a question. The entire path chosen to achieve the goal is the solution to the problem. Thus, the solution of the problem is a process of transformation of conditions aimed at achieving the desired result.

In a student-centered way of learning, working on a financial problem, the teacher and the student are employees. The teacher, talking with a group of students, asks questions "around" the problem. For example, the task: Determine the compound interest rate at which the initial capital is 55 thousand rubles. Will reach the value of 70 thousand rubles. after 7 months with monthly accrual and capitalization of interest. Questions may include: What is a compound interest rate? How is it determined? What variables are missing in the condition? What does monthly interest mean? What do you understand by interest capitalization? How will the decision change if capitalization is not performed? Etc.

In the process of such a conversation, there are no right or wrong answers, there are different positions, different points of view on the method of solution, on the applied knowledge. Students express their thoughts, share their knowledge and experience, discuss what fellow students offer, select, with the help of a teacher, those positions that are most productive in this particular case. The teacher, skillfully maneuvering, directs the students to jointly "work out" all the proposed points of view. As a result of such work, knowledge is born $[17,18]$. And, let's pay attention to the fact that this kind of active work on solving financial problems should, in our opinion, be included in every lesson.

Considering the structure of the discipline "Financial mathematics", it can be noted that it allows you to implement the method of personality-oriented approach with a high degree of efficiency. The course consists of three sections, of which the first is aimed at obtaining theoretical knowledge and studying the main areas of application of the studied science. The second and third sections are aimed at obtaining practical skills in calculating the indicators of financial and insurance operations using the tools of mathematics and the theory of probability.

The organization of work in the study of the first block of the discipline from the standpoint of an individualized approach makes it possible for the teacher to "align" the level of knowledge in the training group. This is achieved by conducting entrance testing, which allows you to determine the general level of theoretical knowledge of students in the field of finance and insurance, practical skills in using the simplest tools of mathematical calculations. Based on the analysis of test results, students can be conditionally divided into subgroups in order to organize joint work. The goal that is set in the study of the first block is to study the conceptual material, determine the scope of use of financial mathematics tools, determine the range of issues studied and the role of mathematics in financial and insurance activities. Discussion platforms allow the teacher to act as a coordinator of the learning process, where students with good initial training can act as trainers, thereby consolidating their knowledge through reports and discussion. Separately, it is worth noting that the teacher does not stand aside as an observer - he leads the process by planning discussion topics, preparing assignments for students and multimedia support for lessons. It should be noted that when building a personality-oriented approach to the learning process of any discipline, when a student takes part in building a learning vector, the availability of a sufficient amount of materials is a prerequisite for the successful achievement of the planned result.

The second and third sections in the study of the discipline are aimed at a detailed study of the structure of calculations of the results of financial transactions and indicators of 
insurance contracts. In this case, the main emphasis is placed on the study of methods for calculating and analyzing operations, on working with the achievement of the required level of understanding of the operations performed and the mathematical apparatus applied to them. The presentation of the material can be structured in a lecture-practical form, when, within the framework of one lesson, a new topic is studied and, together with theoretical material, the practical skill of applying the acquired knowledge in practice is being developed. A personality-oriented learning strategy in this case assumes an alternative choice in solving practical problems, taking into account personal abilities. This approach provides a more comfortable perception of new information and the student, having the opportunity to choose material for practicing practical skills, does not experience difficulties in mastering new calculation methods for him.

The second block of discipline is the calculation of indicators of operations of banks and financial and credit institutions. Students, as a rule, are asked to determine the most effective proposals for the use of funds, form a payment schedule for a loan, and much more. In this case, it seems important to make students understand the need to obtain such knowledge and the possibility of their practical application. Based on the internal nature of calculations, the teacher can organize situational tasks when students act as financial advisors for each other and develop the most effective investment plans and directions for using funds. In this case, it is worth avoiding unnecessary restrictions and requirements for the final solution of the task, but on the other hand, it is necessary to exercise full control over the order of work.

It should be noted that with a competent structure of classes at the first stage of studying the discipline, no more than $10 \%$ of students experience difficulties in solving practical problems. When using discussions, collective analysis of financial problems to be solved, the number of students who can solve problems only at the initial level becomes much smaller.

The third block of the discipline contains calculation methods for key indicators of insurance contracts. It should be noted that this part of the course has a certain specificity and is the most difficult to study, since it requires an understanding and understanding of the nature of insurance and insurance risk. At this stage, students are independent enough to determine in what sequence they will master the sections. The task of the teacher consists in the initial presentation of the material, determining the range of tasks and formulating the control task based on the results of studying this section. The student, as a rule, determines himself over the calculations for which contract he will work, the teacher acts as a consultant and source of information about methods, mathematical apparatus and initial data for calculations. When studying this block, it is possible to conduct a general seminar as a presentation of the results of the work of each student [19].

Thus, in relation to financial problems, from lesson to lesson, from topic to topic, considering tasks in which the parameter is placed in different positions and conditions, while changing the structure of the solution process, more and more new approaches to the solution are being developed. At the same time, it is important in each such solution to focus the attention of students on the differences in the approaches used, on the strengths and weaknesses of each of them. Thus, students acquire their own subjective experience in research activities, experience in working with problems that require possession of a complex of financial and mathematical knowledge. Gradually, financial problems, methods of their solution in the minds of each student acquire their value as a useful component in solving already more complex problems. So the ability to carry out interest calculations, solving issues related to various debt instruments (bills of exchange, certificates of deposit, bonds) will come in handy in conducting econometric calculations related to predicting the behavior of financial markets. And further, stochastic financial mathematics will allow you to freely deal with probabilistic payments and rates. 
The main objective is to obtain an adequate valuation of instruments, taking into account the probabilistic nature of market conditions and the flow of payments from instruments. Formally, this includes the optimization of a portfolio of instruments within the framework of the average variance analysis. Methods for assessing financial risks are also based on models of stochastic financial mathematics. At the same time, in stochastic financial mathematics, it becomes necessary to determine the criteria for assessing risks, including for an adequate assessment of financial instruments, etc. In our opinion, teaching financial mathematics based on a personality-oriented approach, when solving financial problems at each lesson, will lead not only to an understanding of methods and ways of solving the problems themselves, but also to high-quality financial and economic education in general. A deep, content-methodological line of financial tasks, rich in ideas and methods, is the best way to develop the active creative activity of the student, his systemic thinking. And building the learning process on the basis of a personality-oriented approach based on respect for the development goals of each student will be the best way to contribute to his self-development and self-realization.

This approach ensures both the subjectivity of teaching and the subjectivity of the development of each student. Which already implies, obviously, not only training, but education. After all, as you know, training and education are not identical in nature and results. Learning through the acquisition of knowledge, skills, and abilities provides social and professional adaptation in society. Education, in addition to all this, allows you to form an individual perception of the world. All this helps to find in the future the application of the studied issues of financial mathematics, to form a financially literate person.

In addition to lectures and practical classes in financial mathematics, one should not forget about such an element as an independent work [20, 21]. Taking into account the current challenges in the training of top-level specialists $[22,23]$, teachers see in the reorientation of curricula to the widespread use of independent work in the educational process. At Minin University, a significant part of the hours is devoted to contact independent work (CIW) with students, which provides an additional opportunity for the application of a personal approach in teaching bachelors. DAC in financial mathematics allows you to transfer a student from a passive consumer of knowledge to an active creator of knowledge, able to think critically, plan his independent actions, who can take initiative, formulate a problem, analyze ways to solve it, find alternatives and an optimal result, prove its correctness, and also successfully find a way out of the prevailing, often non-standard financial and economic situations.

The student-centered approach is based on the individualization of students' independent work, which includes:

- an increase in the proportion of intensive work with more prepared students;

- dividing the lesson into compulsory and creative parts (for everyone trying to cope with more difficult and, most importantly, non-standard tasks, additional questions, educational problem situations, scientific research, etc.);

- regularity of consultations with students;

- comprehensive and timely information on the content of independent work, deadlines, the need for auxiliary means, forms, methods of monitoring and evaluating the final results with mandatory comparison with the expected [24, 25].

A sufficient number of hours and the systematic implementation of independent work of students within the framework of such a multivariate discipline as "Financial Mathematics" allows you to achieve not only the required level of knowledge, but also allows you to develop such necessary qualities as scientific interest, research interest and others. Competent construction of tasks aimed at organizing independent work will allow you to regulate the gradual development of sections of the discipline, taking into account the level of knowledge of students, gradually moving from topic to topic. This approach gives 
students confidence that the material of the discipline "Financial Mathematics" will be mastered completely in the hours allotted for study.

In this regard, some proposals for the implementation of the discipline "Financial Mathematics" deserve attention, such as:

- organization of individual training plans, rating plans for the discipline with the involvement of students in research work and, if possible, in real design by order of organizations;

- inclusion of contact independent work of students in the curricula of all universities and the schedule of classes with the organization of individual consultations at the departments;

- creation of a set of educational and teaching aids (including electronic) for the implementation of independent work of students;

- orientation of lecture courses to independent work;

- rating method of monitoring students' independent work;

- collegial relations between teachers and students;

- development of tasks involving non-standard solutions.

The competent organization of self-study makes it possible to study the discipline in a distance mode for students who, for a number of reasons, cannot attend classes and are forced to master the course program on their own. With a built learning trajectory, together with the teacher, the student, evaluating his knowledge, sequentially selects tasks from blocks of tasks of various levels of complexity, thereby developing his skills and abilities in the field of economic and mathematical calculations.

\section{Conclusions}

The discipline "Financial Mathematics" is one of the key disciplines in the training of future specialists in the financial and insurance sphere and deserves close attention in terms of organizing the educational process, taking into account the personal characteristics of each student: the initial level of knowledge, the ability to perceive information, assimilation of new material, selection of information sources, the ability to independently study new material and work additionally. A large amount of information of a mathematical nature and the need for a certain level of knowledge of economic terms and concepts presupposes a large amount of work on the part of the teacher to organize competent work with the entire audience. It is natural that the level of perception of information among students is different, therefore it is especially important to implement the educational process separately with each of the students, based on his personal qualities.

The structure of the discipline allows you to organize training with the possibility of developing the skills of independent organization of work by students with varying degrees of teacher participation in this process. Depending on the level of his training and willingness to study the discipline, following his goal of achieving a certain level of knowledge, the student has a good opportunity to organize personal planning within the educational process.

Thus, student-centered teaching of financial mathematics, subject to the constant solution of problems, research of methods for their solution, the use of contact independent work, contributes to the formation of a high-quality financial and economic education of the student, which involves the widespread use of subjective experience in the interpretation and assessment of facts, phenomena of the surrounding world on based on personally significant values and internal attitudes. 


\section{References}

1. O.V. Kharitonova Personality-oriented approach as a model of modern education, In the collection: Innovative teaching of the Russian language in the context of multilingualism, 311-312 (Moscow: RUDN, 2014)

2. M. Studneva, S. Grachev, A. Kostalevskaya Basic principles of a personality-oriented approach to learning, In the collection: Actual questions of psychology and pedagogy in modern conditions, 137-138 (Moscow: Press, 2015)

3. G.A. Sikorskaya, G.N. Loktionova Personality-oriented pedagogy as the basis of specialized education for senior pupils, Education. The science. Scientific personnel, 2, (2011)

4. S.N. Dorofeev Personality-oriented approach as the basis for building individual trajectories of teaching mathematics World of Science, Culture and Education, 2 (30), 48-50 (Gorno-Altaysk, 2013)

5. O.A. Lyapina, S.S. Frolova, N.R. Dudurkina Problem learning as a means of implementing a personality-oriented approach to teaching chemistry, Educational experiment in education, 4, 43-48 (2018)

6. E.S. Perevoznyuk Mathematics lessons within the framework of the concentration of student-centered learning, Mathematics in school, 4, (2006)

7. O.F. Turyanskaya Theoretical Foundations of Personally Oriented Approach to Learning p. 278 (Monography, Oryol: The publ. house of FGBOU VPO "OSU", 2015).

8. I.S. Yakimanskaya Personality-oriented education in modern school p. 96 (Moscow: September, 2006)

9. V.V. Afanasyev, I.V. Afanasyeva Combined approach as a methodological basis for managing a personality-oriented learning process, Materials of the All-Russian scientific and practical conference: Diagnostics of the functioning of pedagogical systems of higher education, 154-157 (Nizhny Novgorod, 1998)

10. V.I. Liseenko Features of personality-oriented education at the university: forms of implementation, features, problems, Young scientist, 15. 530-536 (2017)

11. A.V. Kiryakova The theory of personality orientation in the world of values p. 188 (Monography, Orenburg: OSU, 2000)

12. I.S. Yakimanskaya Psychological foundations of mathematical education p. 320 (Moscow: Academy, 2004)

13. S.M. Gulyants The essence of the personality-oriented approach in teaching from the point of view of modern educational concepts, Bulletin of the Chelyabinsk State Pedagogical University, 2, 40-52 (2009)

14. G.T. Klinkov, M.A. Rodionov, O.E. Kozlova, E.V. Vezetiu, E.V. Vovk Implementation of discussion technologies in a personality-centered professional education, Amazonia Investiga, 26, 82-87 (2020) DOI: 10.34069 / AI / 2020.26.02.9

15. Z.V. Smirnova, O.I. Vaganova, I.S. Vinnikova, A.V. Lapshova, O.V. Golubeva Modern multimedia didactic tools of interactive training. In the collection: Lecture Notes in Networks and Systems. Growth Poles of the Global Economy: Emergence, Changes and Future Perspectives. Plekhanov Russian University of Economics, 485491 (Luxembourg, 2020) DOI: 10.1007 / 978-3-030-15160-7_49 
16. Kh.Kh. Shamanova, E.M. Vishnevskaya Interactive technologies as a means of implementing a personality-oriented approach in teaching, Problems of modern pedagogical education, 62-4, 244-246 (Yalta, 2019)

17. I.V. Abramova Personally-oriented teaching of students as a condition for the formation of their professional competence, Problems of modern teacher education, 59-2, 7-10 (2018)

18. S.R. Khaltaeva, E.Ts. Garmaeva Conditions and problems of the application of a student-centered approach in teaching. In the collection: Proceedings of conferences VSGUTU. Materials of the scientific and methodological conference. East Siberian State University of Technology and Management, 249-252 (2015)

19. A.A. Popkova, O.I. Vaganova, Z.V. Smirnova, E.A. Kuznetsova, I.S. Vinnikova Economic Socialization in University, In the collection: Lecture Notes in Networks and Systems. Growth Poles of the Global Economy: Emergence, Changes and Future Perspectives. Plekhanov Russian University of Economics, 1049-1056 (Luxembourg, 2020) DOI: 10.1007/978-3-030-15160-7_105

20. I.S. Vinnikova, E.A. Kuznetsova, A.K. Zakaria Organization of independent work of students in economic areas of training in the study of financial mathematics, Problems of modern pedagogical education, 60-1, 61-64 (Yalta, 2018)

21. I.S. Vinnikova, E.A. Kuznetsova, Yu.G. Shutova, D.S. Starodubova Pedagogical features of the formation of financial literacy among students of economic training, Internet magazine "World of Science", 4 (6) (2016) http://mirnauki.com/PDF/39PDMN616.pdf

22. V.V. Dobroselsky Personality-oriented approach in training future bachelormanagers, Bulletin of the Southern Federal University. Pedagogical sciences, 10, 125 130 (2017)

23. R. Ferreira Formation of entrepreneurial competencies of a university graduate in the context of the transition to third-generation universities / R. Ferreira, V. G. Lizunkov, E. V. Politsinskaya // Bulletin of NGPU. - 2017. - T. 7, No. 6. - S. 195-211.

24. M.P. Prokhorova, O.I. Vaganova Design and implementation of an educational event in the training of future managers, Vestnik of Minin University, 7 (1), 4 (2019)

25. V.V. Korableva, S.I. Artemyeva Personality-oriented approach in higher education, In the collection: Theoretical and pragmatic aspects of human development in the educational space, 169-172 (2020) 